\title{
EXPERIMENTAL INVESTIGATION OF CHEMICAL ETCHING ON EN-5 STEEL USING NITRIC ACID
}

\author{
Hardeep Singh $^{1}$, Charnjit Singh Kalra ${ }^{2}$, Rahul Mehra ${ }^{3}$ \\ ${ }^{I}$ Student of M.Tech, Dept. of Production Engineering \\ ${ }^{2}$ Assistant Professor, Dept. of Mechanical Engineering, SUSCET TANGORI, Punjab, India \\ ${ }^{3}$ Assistant Professor, Dept. of Mechanical Engineering, SUSCET TANGORI, Punjab, India
}

\begin{abstract}
This experimental investigation analyses the influence of etching conditions on material minimum overcut area during chemical etching process of EN5 steel with etchant nitric acid. Analysis of variance (ANOVA) is employed to investigate the influence of time, temperature and concentration on minimum overcut area of the material. The experiments was conducted to varying the parameters of etching process like temperature from $20^{\circ} \mathrm{c}$ to $30^{\circ} \mathrm{c}$. Time from $2 \mathrm{hrs}$ to $6 \mathrm{hrs}$ and concentration $10 \%$ to $30 \%$ are studied in details according to Taguchi's design of experiments. At last results are analyzed using Taguchi, ANOVA and parametric optimization is done for minimum overcut area of material. From the experimentation, it is concluded that for etching of EN-5 steel optimum machining condition for minimum overcut area with Time (2hrs), Temperature $\left(20^{\circ} \mathrm{c}\right.$ ), and Concentration $(10 \%)$.
\end{abstract}

Keywords: Anova, Overcut Area, Taguchi, Etching, EN-5

\section{INTRODUCTION}

The main objective of this paper is to study different parameters like time, temperature and concentration (hrs, degree Celsius, percentage) of chemical etching process to develop empirical relationships between different process parameters and out responses namely minimum overcut area of material. In (1981) Pandey PC, Shan HS [1] chemical etching is similar to blanking in sheet metals except material is removed by chemical dissolution rather than by shearing. Used in bur free etching of printed circuit boards, decorative panels etc. In (2007) O Cakir [2] studied chemical etching process had regular metal removal rate, tooling cost of the machining is low, during machining burr formation is very low, the work piece machined by chemical etching process was not subjected by stress introduced by tool material. In (2013) [3] Ravinder Chaudhary studied about the EN-5 material is medium strength steel. This material is used in industry to manufacture the rack and pinions, studs bolts, rollers, studs etc. In (2000) H. Sachdev [4] studied about the parameter effects during the etching process. According to the researcher the parameters like temperature, time, concentration can effect on the surface of the material. The MRR of the material was increase with increase in temperature, time and concentration. In (2004) A. Fadaei Tehrani [5] studied about the parameters used in etching process and working on different type of etchants on same one material. During the experiment researcher check the surface roughness of the material when etched the material in different type of solution. In nutshell he selects the etchant which had better MRR and minimum surface roughness on the material.

This necessitates a process optimization to determine optimal values of etching parameters, such as time, temperature and concentration to fully evaluate the performance of etching the materials. The present study is an attempt to achieve this goal when etching EN5 steel.

\section{EXECUTIONS OF EXPERIMENTS}

The ranges of the parameters varied for the experimental work were selected on the basis of results of experiments. The input parameters, which were kept constant during the experimentation, are given below. An experimental optimization is done in calculating the minimum overcut area using these levels.

Table 1 Parameters Available and used for Experimentation

\begin{tabular}{|l|l|l|l|l|}
\hline \multirow{2}{*}{ S.No } & \multirow{2}{*}{ Parameters } & Level & \multicolumn{2}{|l|}{} \\
\cline { 3 - 5 } & & 1 & 2 & 3 \\
\hline 1 & Time (hrs) & 2 & 4 & 6 \\
\hline 3 & Temprature $\left({ }^{\circ} \mathrm{c}\right)$ & 20 & 25 & 30 \\
\hline 3 & Concentration (\%) & 10 & 20 & 30 \\
\hline
\end{tabular}

Taguchi method, a powerful tool in the design of experiment, is to be used to optimize the etching parameters of effective machining of EN5 steel. Determine the S/N ratio, and analysis of variance (ANOVA) for indicating the most significant parameters affecting the machining performance criteria, i.e. minimum overcut area of material.

\section{RESULTS AND DISCUSSIONS}

The investigated results of Minimum overcut area obtained during etching process of EN5 steel. The results were obtained at variation of concentration e.g. from $10 \%$ to $30 \%$, 
temperature e.g. from $20^{\circ} \mathrm{c}$ to $30^{\circ} \mathrm{c}$, and time from $2 \mathrm{hrs}$ to 6 hrs.

\begin{tabular}{|c|c|c|c|c|c|}
\hline$\downarrow$ & C1 & $\mathrm{C} 2$ & C3 & C4 & $C 5$ \\
\hline & Time (hrs) & Temperature(oc) & Concentration \% & overcut area & SNRA1 \\
\hline 1 & 2 & 20 & 10 & 3.25 & -10.2377 \\
\hline 2 & 2 & 25 & 20 & 16.00 & -24.0824 \\
\hline 3 & 2 & 30 & 30 & 72.00 & -37.1466 \\
\hline 4 & 4 & 20 & 20 & 55.00 & .34 .8073 \\
\hline 5 & 4 & 25 & 30 & 119.00 & -41.5109 \\
\hline 6 & 4 & 30 & 10 & 27.00 & -28.6273 \\
\hline 7 & 6 & 20 & 30 & 96.00 & .39 .6454 \\
\hline 8 & 6 & 25 & 10 & 33.00 & .30 .3703 \\
\hline 9 & 6 & 30 & 20 & 133.00 & -42.4770 \\
\hline
\end{tabular}

Fig 1: Showing the results of etching Parameters on Mean of overcut area of material

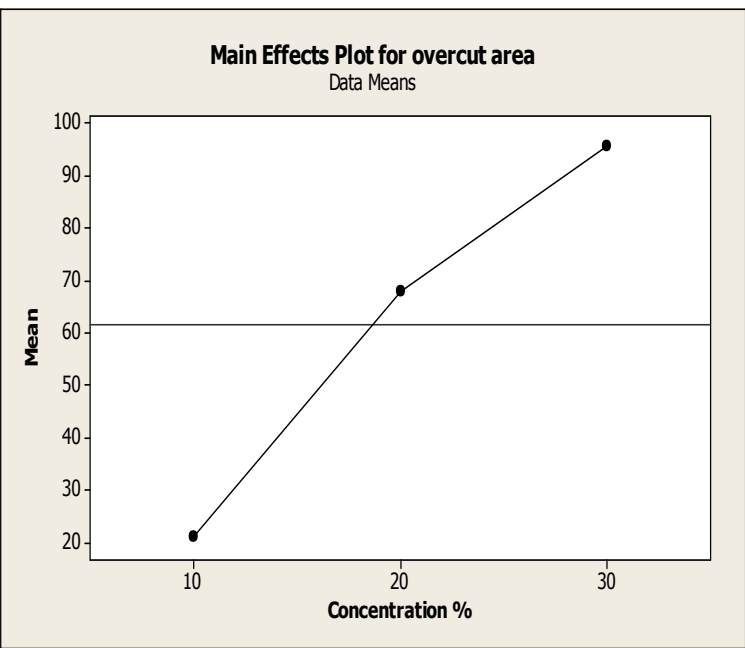

Fig 2: main effects plot for overcut area v/s concentration

In Figure 2, here the value of mean overcut area is increased from 20 to 98 when the concentration is increased from $10 \%$ to $30 \%$. Further the mean increases from 20 to 70 when the concentration is increased from $10 \%$ to $20 \%$. The optimum parameter for concentration is $10 \%$.

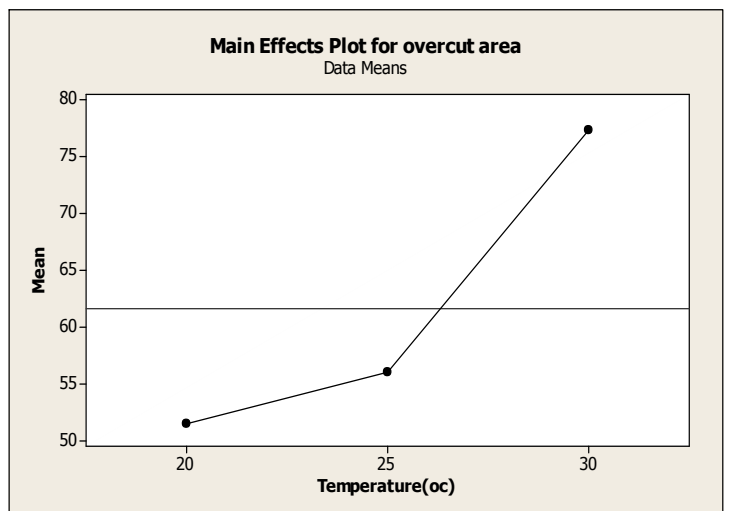

Fig 3 main effects plot for overcut area v/s temperature

In Figure 3, here the value mean effect of overcut area is increased from 50 to 78 when the temperature is increased from $20^{\circ} \mathrm{c}$ to $30^{\circ} \mathrm{c}$. Further the mean of overcut area increases from 50 to 55 when the temperature is increased from $20^{\circ} \mathrm{C}$ to $25^{\circ} \mathrm{c}$. The optimum parameter for current is $20^{\circ} \mathrm{c}$.

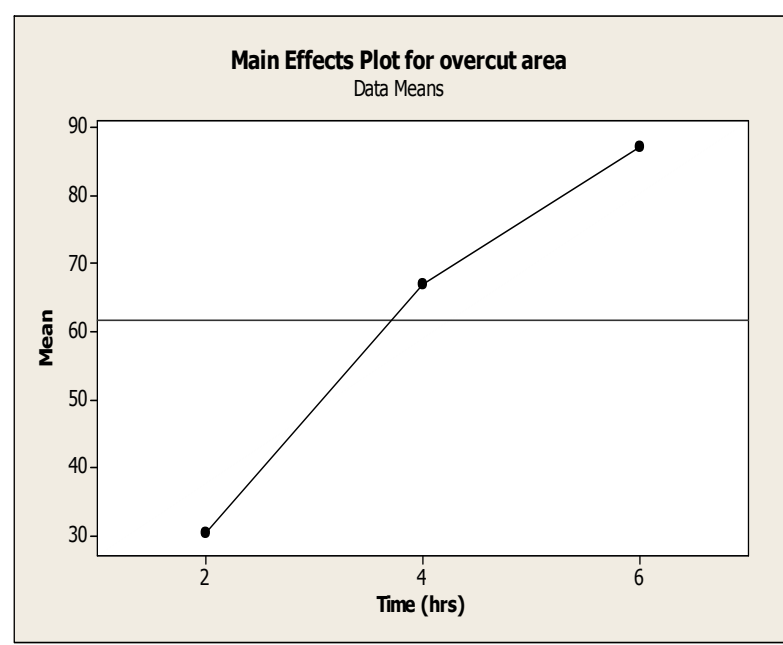

Fig 4 main effects plot for overcut area v/s time

In Figure 4, here the value of mean effect of overcut area is increased from 30 to 88 when the time is increased from $2 \mathrm{hrs}$ to $6 \mathrm{hrs}$. Further the mean increases from 30 to 70 when the time is increased from $2 \mathrm{hrs}$ to $4 \mathrm{hrs}$. The optimum parameter for current is $2 \mathrm{hrs}$.

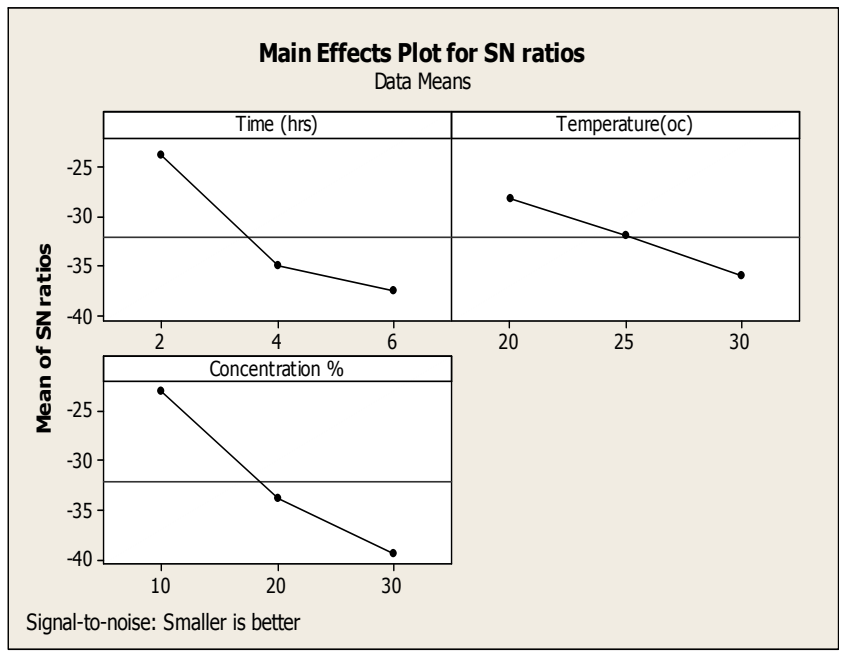

Fig 5 Effect of the Process Parameters on the Mean of S/N ratio

In Fig 5, mean of $\mathrm{S} / \mathrm{N}$ ratio the maximum value of mean in case of time is at $2 \mathrm{hrs}$, for the temperature maximum value of mean is at $20^{\circ} \mathrm{C}$ and maximum mean value for concentration is $10 \%$.

The results are analyzed using ANOVA for identifying the significant factor affecting the performance measure of etching on EN5 steel. An ANOVA result shows that concentration and time are significant factor because their $\mathrm{P}$ values for both are less than .05. Other factor temperature is not significant because their $\mathrm{P}$ value is larger than .05 

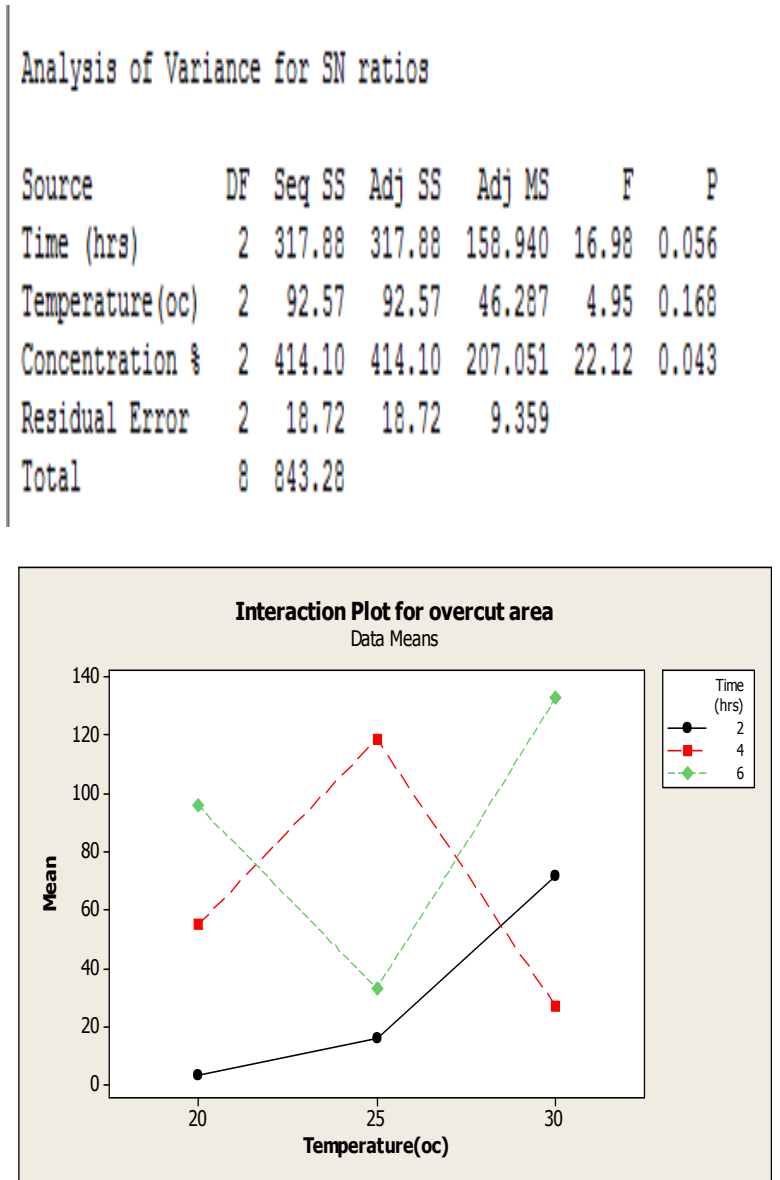

Fig 6 Interaction of Time (hrs) and Temperature $\left({ }^{0} \mathrm{c}\right)$ on overcut area

Fig 6, shows the mean interaction plot of overcut area, time vs. temperature. From this figure it is clear that the value of mean for minimum overcut area is notice at when temperature is $20^{\circ} \mathrm{c}$ at time $2 \mathrm{hrs}$.

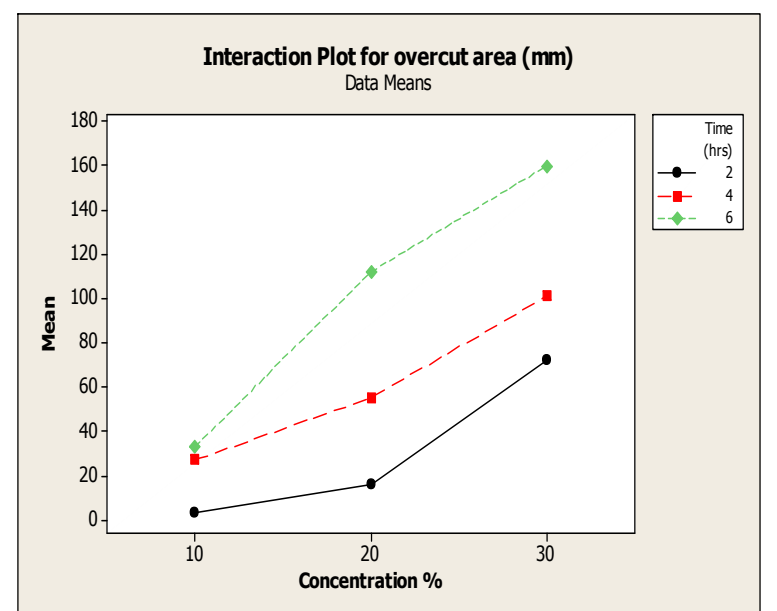

Fig 7 Interaction of Time (hrs) and concentration (\%) on overcut area

Fig 7, shows the mean interaction plot of overcut area, time vs. concentration. From this figure it is clear that the value of mean for minimum overcut area is notice at when time $2 \mathrm{hrs}$ at concentration $10 \%$

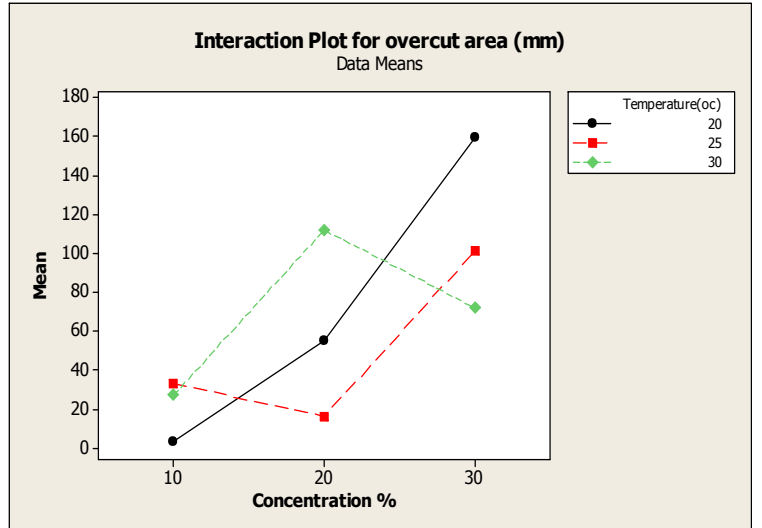

Fig 8 Interaction of concentration $(\%)$ and temperature $\left({ }^{0} \mathrm{c}\right)$ on overcut area

Fig 8, shows the mean interaction plot of overcut area, temperature vs. concentration. From this figure it is clear that the value of mean for minimum overcut area is notice at when temperature is $20^{\circ} \mathrm{c}$ at concentration $10 \%$.

\section{CONCLUSIONS}

1. It is noted that the minimum value of overcut area is $3.25 \mathrm{~mm}^{2}$ which is at $20^{\circ} \mathrm{c}$ temperature, $2 \mathrm{hrs}$ time and $10 \%$ concentration.

2. The minimum mean value for minimum overcut area at temperature $20^{\circ} \mathrm{c}$, time $2 \mathrm{hrs}$ and concentration $10 \%$.

3. The time and concentration are significant factors; temperature is not significant number because its value is 0.168 .

4. In different interaction plot graphs the optimum values of parameters are $20^{\circ} \mathrm{c}$ temperature, $2 \mathrm{hrs}$ time and $10 \%$ concentration.

5. For EN5 material optimum machining condition for minimum overcut area with $20^{\circ} \mathrm{c}$ temperature, $10 \%$ concentration, $2 \mathrm{hrs}$ time.

\section{REFERENCES}

[1]. Pandey PC, Shan HS, Tata Mc Graw Hill education, eBook modern machining processes, (1980)

[2]. O.Çakir, A. Yardimeden, T. Ozben, "chemical machining" archieves of material science and engineering (2007) 499 - 502

[3]. Chaudary Ravinder, Rampal Rohit, Sharma Neeraj "Investigation and Optimization of Materiel Removal Rate for Wire Cut Electro Discharge Machining In EN5 Steel Using Response Surface Methodology" International Journal of Latest Trends in Engineering and Technology (2013) 192- 199

[4]. H. Sachdev , M. Strauß "Selective etching of boron nitride phases" diamond and related materials, (2000) 614619

[5]. A. Fadaei Tehrani, E. Imanian "A new etchant for the chemical machining of St304" journal of material processes technology, (2004) 404-408 